\title{
Mechanism of ATP turnover inhibition in the EJC
}

\author{
KLAUS H. NIELSEN, ${ }^{1,2}$ HALA CHAMIEH, ${ }^{3}$ CHRISTIAN B.F. ANDERSEN, ${ }^{1}$ FOLMER FREDSLUND, ${ }^{1}$ \\ KRISTIANE HAMBORG, ${ }^{1}$ HERVÉ LE HIR, ${ }^{3}$ and GREGERS R. ANDERSEN ${ }^{1,2}$ \\ ${ }^{1}$ Department of Molecular Biology, University of Aarhus, DK-8000 Aarhus, Denmark \\ ${ }^{2}$ Centre for mRNP Biogenesis and Metabolism, University of Aarhus, DK-8000 Aarhus, Denmark \\ ${ }^{3}$ Equipe Labélisée La Ligue, Centre de Génétique Moléculaire, associé aux Universités Paris 6 et Paris 11, CNRS UPR2167, Gif-sur-Yvette, France
}

\begin{abstract}
The exon junction complex (EJC) is deposited onto spliced mRNAs and is involved in many aspects of mRNA function. We have recently reconstituted and solved the crystal structure of the EJC core made of MAGOH, Y14, the most conserved portion of MLN51, and the DEAD-box ATPase eIF4AIII bound to RNA in the presence of an ATP analog. The heterodimer MAGOH/Y14 inhibits ATP turnover by eIF4AIII, thereby trapping the EJC core onto RNA, but the exact mechanism behind this remains unclear. Here, we present the crystal structure of the EJC core bound to ADP-AIF ${ }_{3}$, the first structure of a DEAD-box helicase in the transition-mimicking state during ATP hydrolysis. It reveals a dissociative transition state geometry and suggests that the locking of the EJC onto the RNA by MAGOH/Y14 is not caused by preventing ATP hydrolysis. We further show that ATP can be hydrolyzed inside the EJC, demonstrating that MAGOH/Y14 acts by locking the conformation of the EJC, so that the release of inorganic phosphate, ADP, and RNA is prevented. Unifying features of ATP hydrolysis are revealed by comparison of our structure with the EJC-ADPNP structure and other helicases. The reconstitution of a transition state mimicking complex is not limited to the EJC and eIF4AIII as we were also able to reconstitute the complex Dbp5-RNA-ADP-AIF ${ }_{3}$, suggesting that the use of $\mathrm{ADP}-\mathrm{AlF}_{3}$ may be a valuable tool for examining DEAD-box ATPases in general.
\end{abstract}

Keywords: EJC; AIF; transition state; DEAD-box ATPase; mRNP

\section{INTRODUCTION}

RNA helicases have been proposed to use energy from ATP hydrolysis to unwind double-stranded (ds) nucleic acid or rearrange RNA-protein complexes at virtually all steps of the gene expression pathway (Jankowsky et al. 2001; Fairman et al. 2004; Cordin et al. 2006). Helicases can be classified into five groups based on their sequences. The two largest groups are superfamilies 1 and 2 (SF1 and SF2) in which the helicases contain two RecA like domains with seven conserved motifs I, Ia, II, III, IV, V, and VI (Caruthers and McKay 2002; Singleton and Wigley 2002). The DEAD-box proteins are a ubiquitous subgroup of SF2 enzymes representing the most common type of RNA helicases. DEAD-box proteins like eIF4AIII contain the general helicase motifs and the additional Q and Ib motifs (Cordin et al. 2006). Unwinding of dsRNA and remodeling of mRNP complexes by a variety of DEAD-box ATPases

Reprint requests to: Gregers R. Andersen, Department of Molecular Biology, University of Aarhus, Gustav Wieds Vej 10C, DK-8000 Aarhus, Denmark; e-mail: gra@mb.au.dk, fax: 4586123178.

Article published online ahead of print. Article and publication date are at http://www.rnajournal.org/cgi/doi/10.1261/rna.1283109 have been found to require ATP hydrolysis (Ray et al. 1985; Rozen et al. 1990; Wagner et al. 1998; Svitkin et al. 2001; Bizebard et al. 2004; Fairman et al. 2004; Shu et al. 2004; Yang and Jankowsky 2005). However, the ADP-bound state of DEAD-box proteins may also be involved in RNP remodeling as Dbp5-ADP appears to be responsible for the displacement of the Nab2 protein from RNA (Tran et al. 2007).

Pre-mRNA splicing reactions in higher eukaryotes lead to the deposition of the exon junction complex (EJC) on mature mRNAs at a conserved but sequence-independent position upstream of exon junctions (Le Hir et al. 2000). The EJC constitutes a central effector of mRNA functions that provides an anchoring point successively for nuclear and cytoplasmic factors participating in mRNA transport, translation, and quality control until it most likely is displaced by ribosomes during the first round of translation (Tange et al. 2004). The core of the EJC can be reconstituted in vitro as a complex consisting of eIF4AIII bound to ATP, the most conserved part of MLN51 and the heterodimer MAGOH/Y14 on poly uracil mimicking mRNA (Ballut et al. 2005). In the presence of RNA and MLN51, eIF4AIII slowly hydrolyzes ATP while MAGOH/ Y14 essentially inhibits the turnover of ATP when associating with eIF4AIII, MLN51, and RNA (Ballut et al. 2005), but 
the mechanism of inhibition has not been elucidated (Le Hir and Andersen 2008). At least two different mechanisms can explain the function of MAGOH/Y14 in the EJC: either it inhibits ATP hydrolysis by eIF4AIII (prehydrolysis inhibition) or ATP hydrolysis can occur, and instead, it prevents conformational changes of eIF4AIII upon ATP hydrolysis, normally leading to the release of the products, ADP, and inorganic phosphate (posthydrolysis inhibition) (Le Hir and Andersen 2008).

In order to elucidate the relationship between the stability of the EJC and the nucleotide state of its DEADbox ATPase eIF4AIII, we have determined the structure of the EJC in complex with the transition state analog ADP$\mathrm{AlF}_{3}$ and analyzed the hydrolysis of ATP inside assembled EJC. Additionally, we show that $\mathrm{ADP}-\mathrm{AlF}_{3}$ can promote stable binding of DEAD-box proteins to RNA in other complexes than the EJC. Finally, by comparison with other known structures we discuss common features between SF1 and SF2 helicases.

\section{RESULTS}

\section{The structure of EJC in complex with $\mathrm{ADP}_{-} \mathrm{AIF}_{3}$ mimicking the transition state}

We and others recently determined the crystal structure at $\sim 2.3 \AA$ resolution of a minimal reconstituted EJC in complex with a nonhydrolysable ATP analog, ADPNP, and a poly uracil oligonucleotide mRNA mimic (Andersen et al. 2006; Bono et al. 2006). To further investigate the mechanism of ATP hydrolysis within DEAD-box ATPases, we determined the crystal structure of EJC in complex with the transition state analog $\mathrm{ADP}-\mathrm{AlF}_{3}$ (hereafter called EJC$\mathrm{AlF}_{3}$ ) at the same resolution (Fig. 1; Table 1). Two EJCs are found in the asymmetric unit, and they show subtle differences. In complex II, MAGOH and Y14 are more mobile than in complex I, most likely due to crystal packing effects. Therefore, in the following, we describe only complex I. The distances between the aluminium atom and the axial oxygens (Fig. 1E) are indicative of a dissociative mechanism in which bond breaking has occurred and displays a metaphosphate-like or loose transition state (Wittinghofer 2006). The overall structure is nearly identical to the EJC-ADPNP structure except for the $\gamma$-phosphate environment, where the $\mathrm{AlF}_{3}$, mimicking the planar leaving $\gamma$-phosphate, has moved $0.7 \AA$ toward the catalytic water $\left(\mathrm{w}_{\mathrm{c}}\right)$ that remains at the same position (Fig. 2A). The $\mathrm{AlF}_{3}$ is placed between the catalytic water and a $\beta$-phosphate oxygen in a classical transition state geometry with the leaving group coordinated by Arg367 and Arg370 in eIF4AIII (Figs. 1E, 2B). Very similar transition state geometries are seen in the UvrD helicase, the $\mathrm{F}_{1}$-ATPase and the GTPase Ras in complex with the GTPase activating protein (GAP) (Fig. 2C-E). VASA is a DEAD-box helicase from Drosophila melanogaster that
A

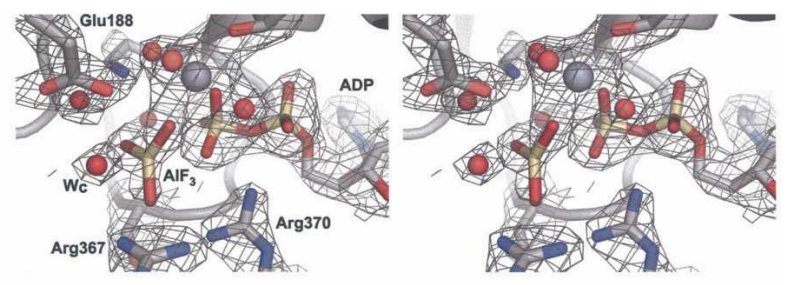

B

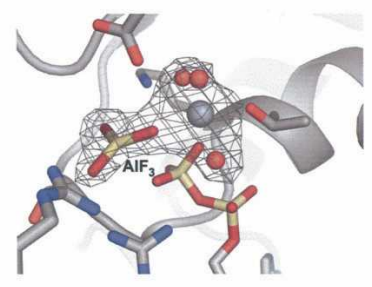

$\mathrm{D}$

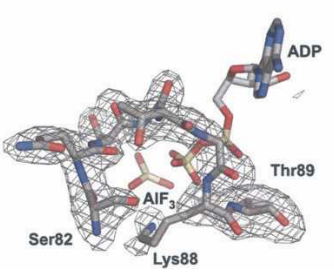

$\mathrm{C}$

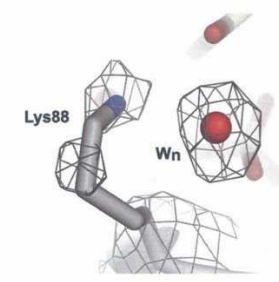

E

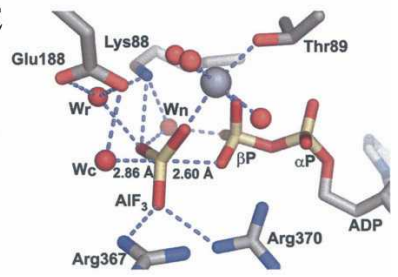

FIGURE 1. Electron density maps of the $\mathrm{ADP}-\mathrm{AlF}_{3}$ binding site. $(A)$ Stereo view of a SIGMAA weighted $3 \mathrm{~F}_{\mathrm{o}}-2 \mathrm{~F}_{\mathrm{c}}$ electron density map contoured at $1.3 \sigma$. $(B-D) \mathrm{F}_{\mathrm{o}}-\mathrm{F}_{\mathrm{c}}$ omit maps, using simulated annealing started at $2000 \mathrm{~K}$, contoured at $3.5 \sigma$ of either $(B)$ the $\mathrm{ADP}-\mathrm{AlF}_{3}$ and $\mathrm{Mg}^{2+}$ with its three coordinating waters omitted. (C) Lys 88 and a nearby water molecule $\left(\mathrm{w}_{\mathrm{n}}\right)$ omitted. $(D)$ motif I (also known as the P-loop or Walker A motif) omitted. (E) Coordination of $\mathrm{AlF}_{3}$ with selected side chains, $\mathrm{ADP}$, and the catalytic water $\left(\mathrm{w}_{\mathrm{c}}\right)$, the relay water $\left(\mathrm{w}_{\mathrm{r}}\right), \mathrm{w}_{\mathrm{n}}$ and three $\mathrm{Mg}^{2+}$ coordinating waters. All densities are displayed on top of complex I. Carbon atoms are colored gray, nitrogen atoms blue, phosphorous atoms wheat, and oxygen atoms red. The magnesium ion is shown in gray as a sphere that is larger than the red water molecules. The $\mathrm{AlF}_{3}$ is colored as the phosphates. This color scheme is used in all figures.

regulates translation of specific mRNAs encoding factors essential for development. We previously proposed (Andersen et al. 2006), based on comparison with the structure of VASA (Sengoku et al. 2006), that coordination of the magnesium ion by Thr89 could be important in keeping the EJC in a prehydrolysis state. This is not supported, since we observe no change for Thr89 in the transition state. The main differences between the two structures with ADPNP or $\mathrm{ADP}-\mathrm{AlF}_{3}$ occur in motif I where side chains of Ser82, Ser84, and Lys88 have changed conformations (Fig. 2A,F). In a number of other structures of G-proteins and ATPases, the equivalent of Lys88 coordinates both the $\beta$-phosphate oxygen and the leaving group (Fig. 2C-E); however, in our structure, the side chain has moved and instead a water $\left(\mathrm{w}_{\mathrm{n}}\right)$ is located between the $\mathrm{AlF}_{3}$ and the $\beta$-phosphate (Figs. 1C,E, 2F). This water may originate from the $\mathrm{w}_{\mathrm{a}}$ molecule coordinated by Ser84 in EJC-ADPNP but absent in EJC-AlF 3 (Fig. 2F). The Lys88 methylene groups are mobile, thereby enabling the amino group to coordinate the $\gamma$-phosphate during its migration from the $\beta$-phosphate to the catalytic water (Figs. 1, 2). 
TABLE 1. Statistics of the crystallographic analysis of the crystal structure

\begin{tabular}{|c|c|}
\hline \multicolumn{2}{|l|}{ Data collection } \\
\hline Beam line & ESRF ID23-1 \\
\hline Wavelength $(\AA)$ & 0.91745 \\
\hline Space group & $\mathrm{C} 2$ \\
\hline Unit-cell parameters & $\begin{array}{l}a=182.04 \AA \\
b=100.75 \AA \\
c=145.88 \AA \\
\beta=112.076^{\circ}\end{array}$ \\
\hline Unique reflections & 107,634 \\
\hline Resolution $(\AA)^{\mathrm{a}}$ & $39-2.3(2.4-2.3)$ \\
\hline Redundancy ${ }^{\mathrm{a}}$ & $4.60(4.59)$ \\
\hline Completeness (\%) ${ }^{a}$ & $99.1(96.0)$ \\
\hline Mean $I / \sigma(I)^{\mathrm{a}}$ & $11.35(2.58)$ \\
\hline$R_{\text {merge }}(\%)^{\mathrm{a}, \mathrm{b}}$ & $10.8(66.6)$ \\
\hline \multicolumn{2}{|l|}{ Refinement } \\
\hline Resolution $(\AA)$ & $39-2.3$ \\
\hline$R$-factor $(\%)^{\mathrm{C}}$ & 20.6 \\
\hline$R$-free $(\%)^{\mathrm{d}}$ & 25.1 \\
\hline Reflections (work/test) & $105,490 / 2144$ \\
\hline \multicolumn{2}{|l|}{ Number of atoms } \\
\hline Protein & 11,182 \\
\hline Ligands (ADP, $\mathrm{AlF}_{3}, \mathrm{Mg}^{2+}$, and RNA) & 298 \\
\hline Water & 380 \\
\hline \multicolumn{2}{|l|}{ RMS deviation } \\
\hline Bonds $(\AA)$ & 0.009 \\
\hline Angles $\left({ }^{\circ}\right)$ & 1.215 \\
\hline \multicolumn{2}{|l|}{ Ramachandran (\%) } \\
\hline Most favored & 89.7 \\
\hline Additionally allowed & 9.9 \\
\hline Generously allowed & 0.4 \\
\hline Disallowed & 0.0 \\
\hline
\end{tabular}

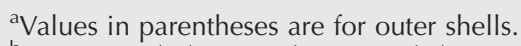

${ }^{\mathrm{b}} R_{\text {merge }}=\left(\Sigma_{h} \Sigma_{j=1, N}\left|I_{h}-I_{h}(j)\right| \Sigma N \times I_{h}\right)$ for the intensity of reflection $h$ measured $\mathrm{N}$ times.

${ }^{\mathrm{C}} R$-factor $=\Sigma_{h}\left|\mathrm{~F}_{\mathrm{o}}\right|-\left|\mathrm{F}_{\mathrm{c}}\right| / \Sigma_{h}\left|\mathrm{~F}_{\mathrm{o}}\right|$, where $\mathrm{F}_{\mathrm{c}}$ is the calculated structure factor scaled to $\mathrm{F}_{\mathrm{O}}$.

${ }^{\mathrm{d}} R$-free is identical to $R$-factor on a subset of test reflections not used in refinement.

Both Ser82 and Ser84 in motif I have their alcohol group flipped compared with EJC-ADPNP (Fig. 2A,F), but single mutations of these amino acids to alanines still allow stable EJC assembly (data not shown). A stable EJC can also be assembled with eIF4AIII Lys88 mutated to alanine (Ballut et al. 2005). The $\mathrm{C}$ terminus of MAGOH interacts with motif I in eIF4AIII through a water bridging the backbone carbonyl of Pro145 in MAGOH with Ser82 and Thr86 in eIF4AIII in EJC-ADPNP (Andersen et al. 2006). This interaction is weakened in our new structure as Ser82 no longer coordinates this water $(\mathrm{w})$ but instead the $\mathrm{w}_{\mathrm{n}}$ molecule (Fig. 2F).

Results from Noble and Song (2007) tentatively suggested that hydrolysis can take place within EJC in vitro, but firm evidence for this has so far not been presented. To test the efficiency of EJC core assembly in the presence of different nucleotides, we performed coprecipitations with polyU ssRNA biotinylated at the $3^{\prime}$ end. This RNA was mixed with the EJC core recombinant proteins and incubated with various nucleotides before precipitation with streptavidin beads. We observed that the EJC is not efficiently assembled in the presence of ADP and inorganic phosphate $\left(\mathrm{P}_{\mathrm{i}}\right)$ (Fig. 3A, cf. lanes 4 and 8 ). In contrast, we could detect EJC- $\mathrm{AlF}_{3}, \mathrm{EJC}-\mathrm{ADPNP}, \mathrm{EJC}-\mathrm{ADP}-\mathrm{BeF}_{3}{ }^{-}$and EJC-ATP (Fig. 3A, lanes 5-7,9). Identical results were obtained making use of TAP-MAGOH/Y14 to precipitate formed EJC using calmodulin beads (data not shown). Within the EJC-ADP- $-\mathrm{BeF}_{3}{ }^{-}$complex, the $\mathrm{ADP}-\mathrm{BeF}_{3}{ }^{-}$ most likely behaves as an ATP analog with an oxygen from the ADP $\beta$-phosphate acting as a ligand to the Beryllium atom (Kagawa et al. 2004). To investigate whether the EJCADP- $\mathrm{P}_{\mathrm{i}}$ complex could be obtained by starting from EJC$\mathrm{ATP}$, we reconstituted the EJC with either $\mathrm{ATP}^{32} \mathrm{P}$ or ATP $\gamma^{32} \mathrm{P}$, purified it, and analyzed its content of ATP and ADP or $\mathrm{P}_{\mathrm{i}}$, respectively, with thin-layer chromatography. Using this approach, we observed both ADP and $\mathrm{P}_{\mathrm{i}}$ in the EJC assembled with wild type eIF4AIII (Fig. 4, lanes 6,9, respectively). As controls, only background level of ATP was observed when the EJC was not assembled (in the absence of eIF4AIII, Fig. 4, lanes 4,7). Varying the incubation times for EJC formation, 20 min versus $60 \mathrm{~min}$, showed nearly identical results (Fig. 4, cf. lanes 5,6 and 8,9 ) and the amount of ATP was in all cases similar to the background, suggesting that the ATPase reaction occurred fast and is likely to be irreversible. These results demonstrated that the EJC is stable in the ADP- $\mathrm{P}_{\mathrm{i}}$ state and that ATP hydrolysis was catalyzed by eIF4AIII inside the EJC because no $P_{i}$ was observed when the EJC was assembled with an eIF4AIII mutant inactive for ATP hydrolysis (Ballut et al. 2005, and data not shown).

The formation of stable complexes between DEAD-box proteins and RNA in the presence of $\mathrm{ADP}-\mathrm{AlF}_{3}$ and $\mathrm{ADP}-$ $\mathrm{BeF}_{3}{ }^{-}$is not limited to the EJC. Indeed, we observed a stable binary complex between eIF4AIII and MLN51 to RNA in the presence of either ADPNP, $\mathrm{ADP}-\mathrm{BeF}_{3}{ }^{-}$, or $\mathrm{ADP}-\mathrm{AlF}_{3}$ (Fig. 3A), but not with ATP or ADP, as demonstrated earlier (Ballut et al. 2005). To demonstrate that the ATP analogs may be used for other DEAD-box ATPases besides eIF4AIII, we investigated the functionally unrelated Saccharomyces cerevisiae Dbp5 involved in nuclear export of mRNP (Snay-Hodge et al. 1998) and which has been demonstrated to bind single-stranded RNA in the presence of ADPNP (Weirich et al. 2006). A crucial step in export is the release of mRNP at the cytosolic face of the nuclear pore complex (NPC), making the export process directional. Dbp5 is thought to participate in this step by remodeling the mRNP to remove the export factor Mex67 from the mRNP. This facilitates the passage through the NPC (Lund and Guthrie 2005) and prevents the return of the mRNP to the nucleus. An $\mathrm{N}$ terminally truncated Dbp5 formed highly stable complexes with poly uracil in the presence of $\mathrm{ADP}-\mathrm{AlF}_{3}$ or $\mathrm{ADP}-\mathrm{BeF}_{3}{ }^{-}$(Fig. 3B, lanes $3,5)$, less stable complexes with ADPNP or $\mathrm{ADP}-\mathrm{MgF}_{3}{ }^{-}$ 

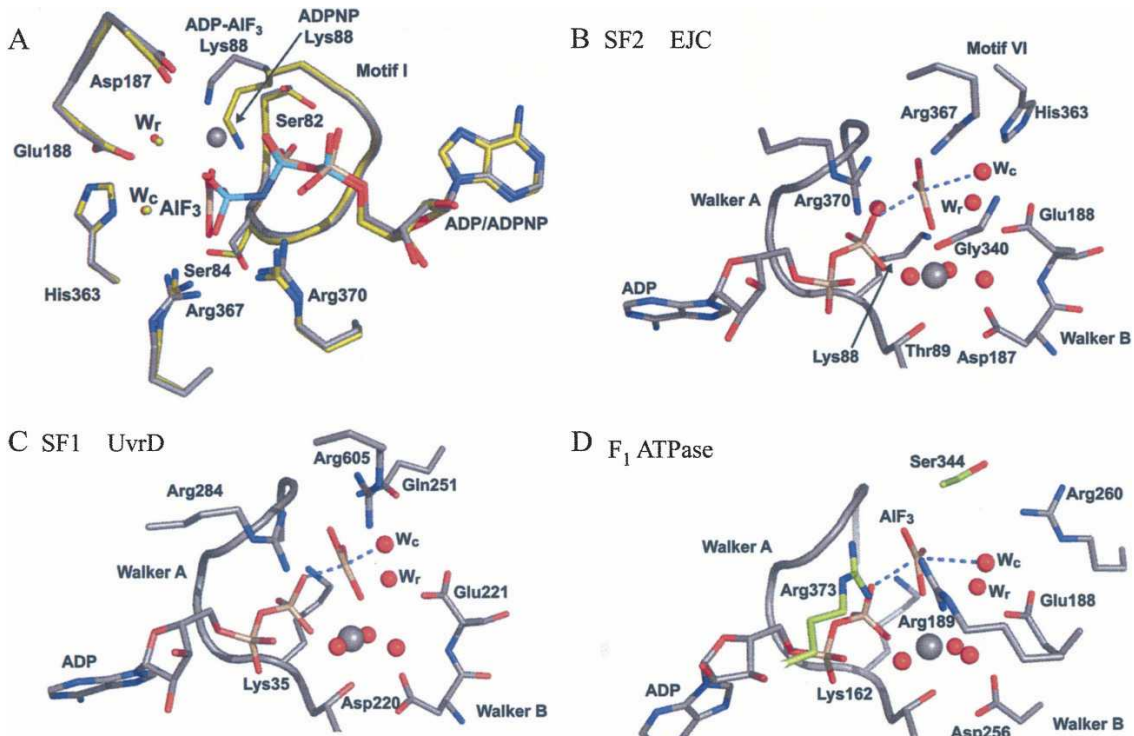

D $\mathrm{F}_{1}$ ATPase

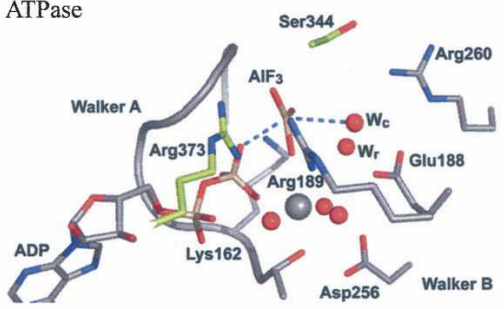

E Ras-GAP

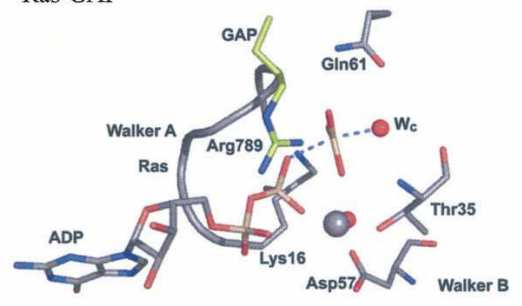

$\mathrm{F}$

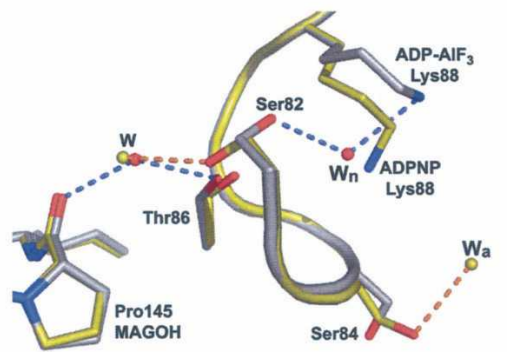

FIGURE 2. Surroundings of the ADP-AlF 3 and comparison with the EJC-ADPNP and three other related transition state structures. (A) Overlay of EJC-ADPNP (Andersen et al. 2006) and $\mathrm{EJC}-\mathrm{ADP}-\mathrm{AlF}_{3}$ showing motif I as a ribbon together with selected residues and ADPNP or $\mathrm{ADP}-\mathrm{AlF}_{3}$. The EJC-ADPNP is shown with carbon atoms and water molecules colored lime and the phosphorous atoms colored cyan. $(B)$ Surroundings of the ADP-AlF $F_{3}$ and motif I with selected side chains in EJC. $(C)$ As in $(B)$, but of the UvrD helicase (Lee and Yang 2006), a superfamily I DNA helicase. $(D)$ As in $(B)$, but of the $\mathrm{F}_{1}$-ATPase (Braig et al. 2000) with $\beta$ subunit carbon atoms in gray and $\alpha$-subunit carbon atoms in lime. $(E)$ As in $(B)$, but of the Ras-GAP complex (Scheffzek et al. 1997) with GAP carbon atoms in lime. In all structures a catalytic water $\left(w_{c}\right)$ is found at a similar position, while in the three ATPases a nearby water molecule $\left(\mathrm{w}_{\mathrm{r}}\right)$ is observed that may function in a proton relay during catalysis. Instead of having one "arginine finger" as in classic G-proteins $(E)$, two "arginine fingers" are found in the ATPases. See Table 2 for comparison of distances between the two axial ligands: the catalytic water and the closest $\beta$-phosphate oxygen. $(F)$ Close-up of motif I and its contact with $\mathrm{MAGOH}$ Prol45. The $\mathrm{w}_{\mathrm{n}}$ water molecule is only observed in the EJC-ADP-AlF 3 complex, and the $\mathrm{w}_{\mathrm{a}}$ water molecule is only observed in the EJC-ADPNP complex.

(Fig. 3B, lanes 4,6), while no complex was observed with ADP (Fig. 3B, cf. lanes 2 and 7).

Our results demonstrate how $\mathrm{ADP}-\mathrm{AlF}_{3}$ can be used as a transition state analog for DEAD-box ATPases, and that MAGOH/Y14 locks EJC in a conformation that allows ATP hydrolysis but prevent the release of the products.

\section{DISCUSSION}

\section{Stabilization of EJC by MAGOH/Y14}

A unique feature of the EJC is its stable association with mature mRNAs from splicing to the first cycle of translation. The stability of the EJC core is conferred by the association of the heterodimer MAGOH/Y14 with the otherwise unstable eIF4AIII-MLN51RNA-ATP complex (Ballut et al. 2005). The results presented in this study suggest that the EJC stabilization ensured by MAGOH/Y14 is not due to an inhibition of the catalytic activity of eIF4AIII per se (prehydrolysis inhibition). Indeed, ATP hydrolysis can occur inside the EJC (Fig. 4) strongly suggesting that the tight association with MAGOH/Y14 prevents release of $\mathrm{ADP}, \mathrm{P}_{\mathrm{i}}$, and $\mathrm{RNA}$ from eIFAIII (posthydrolysis inhibition) that would make hydrolysis irreversible (Le Hir and Andersen 2008). Our results are in agreement with the original observation that MAGOH/Y14 inhibit the turnover ATPase activity of eIF4AIII as part of the EJC core (Ballut et al. 2005). Our demonstration of a stable EJC in the presence of ADP- $\mathrm{P}_{\mathrm{i}}$ is in excellent agreement with a recent kinetic study of the Escherichia coli DEAD-box ATPase DbpA associated with ribosome biogenesis (Henn et al. 2008). This study showed that both ATP hydrolysis and $\mathrm{P}_{\mathrm{i}}$ release limits the ATPase cycle, and that the DbpA-ATP-rRNA and DbpA-ADP-P - -rRNA complexes occur at frequencies of $53 \%$ and $33 \%$, respectively, at steady state (Henn et al. 2008). Hence, for both the EJC and DbpArRNA complexes, a large fraction appears to exist in the ADP- $P_{i}$ state.

\section{The transition state of helicases}

In most crystal structures of G-proteins and ATPases the distance between the two axial oxygens coordinating the planar $\gamma$-phosphate analog (here $\mathrm{AlF}_{3}$ ) is shorter than $4.5 \AA$ (Table 2), whereas we observe a distance of $5.3 \AA$. Although we cannot rule out that this may be slightly shorter in the transition state of DEAD-box ATPases in general, we believe that our structure provides a very good approximation. The distance between the catalytic water and the $\beta$ phosphate oxygen is $4.9 \AA$ in the ADPNP bound state of VASA (Sengoku et al. 2006). In addition, the small GTPase Rac1, which has a distance of $5.4 \AA$ in the transition mimicking state (Table 2), has been demonstrated to be active in ATP hydrolysis (Stebbins and Galan 2000).

The differences between the structures of the EJC in the ADPNP state and in the transition state occur only in the 
A

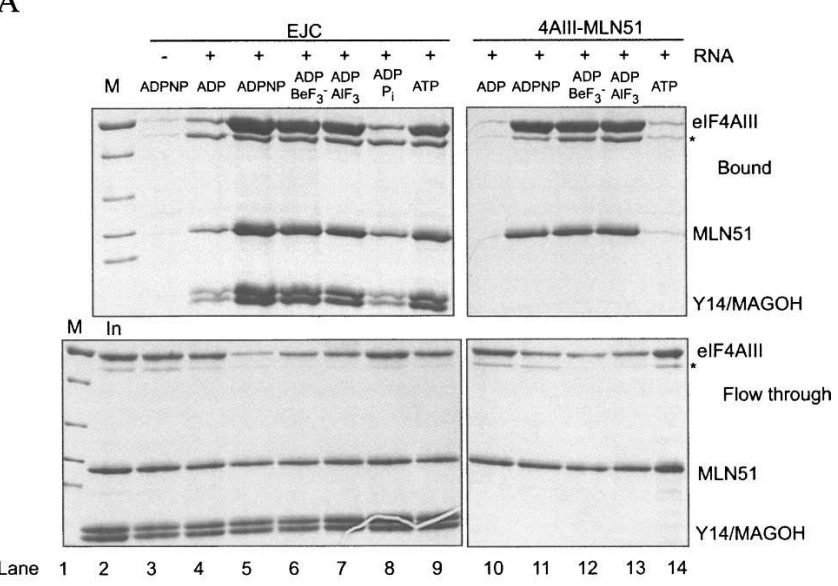

$\mathrm{B}$

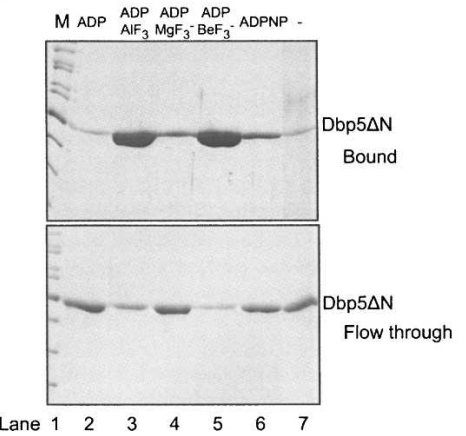

FIGURE 3. RNA binding to DEAD-box ATPases. (A) Streptavidin pull-down of EJC components (top panels, Bound) that were incubated with the indicated nucleotides at $18^{\circ} \mathrm{C}$ overnight together with streptavidin-agarose beads and poly $\mathrm{U}_{30}$-biotin. An aliquot was removed (bottom panels, Flow through) before the beads were thoroughly washed and the bound protein was eluted by boiling the beads in SDS sample buffer. The concentration of inorganic phosphate was $5 \mathrm{mM}$. (B) Same as in $(A)$, but the reaction mixtures contained Dbp5 and the indicated nucleotides and were incubated for only $1 \mathrm{~h}$ at room temperature. A degradation band of eIF4AIII marked ${ }^{*}$ in $(A)$ most likely corresponds to eIF4AIII without the 22 amino acids in the N-terminal known to be unstructured (Andersen et al. 2006).

vicinity of the $\gamma$-phosphate, and this potentially has implications for the dsRNA unwinding activity of DEADbox helicases. To our knowledge, unwinding has not been observed with nonhydrolysable ATP analogs or mutants unable to hydrolyze ATP for any DEAD-box ATPase (Ray et al. 1985; Rozen et al. 1990; Svitkin et al. 2001; Bizebard et al. 2004; Shu et al. 2004; Yang and Jankowsky 2005). VASA, DedI, eIF4AI and other helicases can unwind blunt end dsRNA (Rogers et al. 1999; Cordin et al. 2006; Sengoku et al. 2006; Yang and Jankowsky 2006) but ATP hydrolysis is required. Therefore, these proteins must be able to bind dsRNA in the ATP state with the RNA binding site between the two helicase core domains more open than in the VASAADPNP-RNA structure. We envision that in DEAD-box helicases an open conformation in the ATP state with room for dsRNA must exist. This changes to a closed conformational with ATP bound (as observed in the VASA structure). Unwinding occurs during formation of the closed conformation. In this conformation the nucleotide can be present in the ATP state, the transitions state, or the $\mathrm{ADP}+\mathrm{P}_{\mathrm{i}}$ state. In the EJC, hydrolysis appears to be irreversible, but this may not be the case for other DEAD-box proteins. Dissociation of ADP, $\mathrm{P}_{\mathrm{i}}$, and RNA from the helicase forms the empty conformation (Fig. 5A, unwinding helicase). For the EJC, eIF4AIII is in the closed conformation with ssRNA bound in both the ATP state, transition state, and post-hydrolysis state that predominate. The post-hydrolysis state is stable due to Y14/MAGOH, and the empty conformation is presumable induced by an outer force like the ribosome, which triggers release of MAGOH/Y14 followed by release of RNA, ADP, and $\mathrm{P}_{\mathrm{i}}$ (Fig. 5A, EJC).

To our knowledge, this is the first demonstration of a stable DEAD-box-RNA trapped in a complex mimicking the ATPase transition state. The finding that $\mathrm{ADP}-\mathrm{AlF}_{3}$ allows complex formation with two different DEAD-box ATPases (eIF4AIII and Dbp5; Fig. 3) suggests that ADP--AlF 3 could be an important tool for analyzing DEAD-box proteins in general, not only for structural investigations but also when studying the enzymatic properties of DEAD-box proteins.

\section{Unifying aspects of ATP hydrolysis between SF1 and SF2 ATPases}

Crystal structures of the SF1 helicases PcrA (Velankar et al. 1999) and UvrD (Lee and Yang 2006) in complex with ADPNP and ds DNA with a 3' single-stranded region have been determined. Importantly, the structure of UvrD in complex with ADP and $\mathrm{MgF}_{3}{ }^{-}$mimicking the ATPase transition state (Fig. 2C) in a manner similar to that of

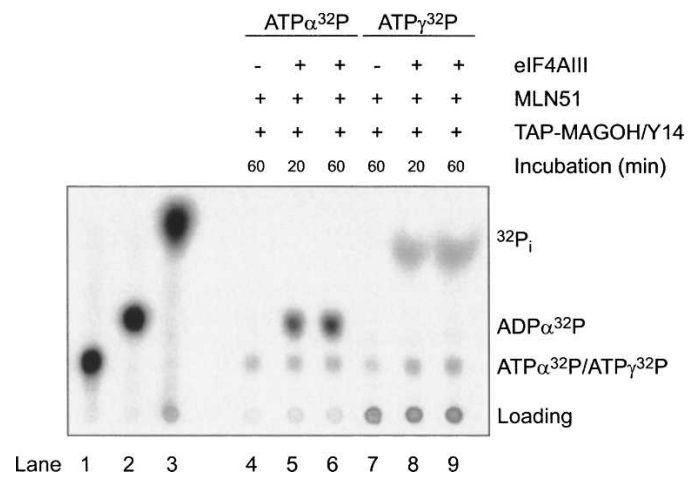

FIGURE 4. ATP hydrolysis can occur in the EJC. Thin-layer chromatography of ATP- $\alpha^{32} \mathrm{P}$ (lane 1), ATP $-\alpha^{32} \mathrm{P}$ treated with recombinant human Upf1 showing the position of $\mathrm{ADP}-\alpha^{32} \mathrm{P}$ (lane 2) and ATP- $\gamma^{32} \mathrm{P}$ treated with recombinant human Upfl showing the position of the inorganic phosphate (lane 3). Purified EJC and controls (purified via TAP-MAGOH/Y14) formed with the indicated components in the presence of ATP- $\alpha^{32} \mathrm{P}$ (lanes 4-6) or in the presence of ATP- $\gamma^{32} \mathrm{P}$ (lanes 7-9) that have been incubated for the indicated times. 
TABLE 2. Distances between the two axial ligands, the catalytic water, and the closest $\beta$-phosphate oxygen, of the $\gamma$-phosphate mimic $\left(\mathrm{AlF}_{3}, \mathrm{AlF}_{4}{ }^{-}\right.$or $\left.\mathrm{MgF}_{3}{ }^{-}\right)$

\begin{tabular}{|c|c|c|}
\hline Structure and reference & Pdb entry & Axial distance $(\AA)$ \\
\hline GTPase activating protein SPTP in complex with Rac, GDP, and AlF $_{3}$ (Stebbins and Galan 2000) & $1 \mathrm{~g} 4 \mathrm{u}$ & 5.4 \\
\hline $\begin{array}{l}\text { Bovine mitochondrial } F_{1} \text {-ATPase bound to ADP, } \mathrm{AlF}_{3} \text {, and ADPNP. Two catalytic sites occupied } \\
\text { (Braig et al. 2000) }\end{array}$ & $1 \mathrm{e} 1 \mathrm{r}$ & 5.3 \\
\hline EJC-ADP-AlF 3 , complex 1 & $3 e x 7$ & $5.3^{\mathrm{a}}$ \\
\hline EJC-ADP-AlF ${ }_{3}$, complex 2 & $3 e x 7$ & 5.1 \\
\hline GYP1 TBC domain in complex with Rab33, GDP, and $\mathrm{AlF}_{3}$ (Pan et al. 2006) & $2 \mathrm{~g} 77$ & 4.7 \\
\hline RasGAP in complex with Ras, GDP, and $\mathrm{AlF}_{3}$ (Scheffzek et al. 1997) & $1 \mathrm{wq} 1$ & 4.5 \\
\hline Cdc42GAP in complex with Cdc42, GDP, and $\mathrm{AlF}_{3}$ (Nassar et al. 1998) & 1grn & 4.4 \\
\hline GAP domain of ExoS toxin in complex with Rac, GDP, and $\mathrm{AlF}_{3}$ (Wurtele et al. 2001) & 1he1 & 4.3 \\
\hline RhoGAP in complex with RhoA, GDP, and $\mathrm{MgF}_{3}{ }^{-}$(Graham et al. 2002) & 1ow3 & 4.2 \\
\hline Bovine mitochondrial $\mathrm{F}_{1}$-ATPase bound to $\mathrm{ADP}_{-} \mathrm{AlF}_{4}{ }^{-}$. Three catalytic sites occupied (Menz et al. 2001) & $1 \mathrm{~h} 8 \mathrm{e}$ & 4.2 \\
\hline $\mathrm{G}_{\mathrm{i} \alpha 1}$ subunit in complex with GDP and $\mathrm{AlF}_{4}^{-}$(Coleman et al. 1994) & 1gfi & 4.1 \\
\hline Mnme G-domain in complex with GDP and $\mathrm{AlF}_{4}{ }^{-}$(Scrima and Wittinghofer 2006) & 2gj8 & 4.1 \\
\hline UvrD-DNA-ADP, and $\mathrm{MgF}_{3}{ }^{-}$complex (Lee and Yang 2006) & 2is6 & 3.9 \\
\hline Vasa-RNA-ADPNP complex (Sengoku et al. 2006) & $2 \mathrm{db} 3$ & 4.9 \\
\hline
\end{tabular}

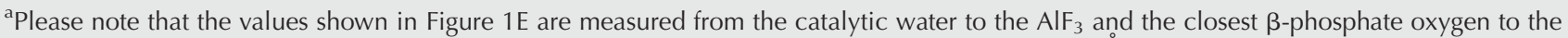
$\mathrm{AlF}_{3}$, respectively. Since the inline angle is not $180^{\circ}$, the sum of the two numbers exceeds the $5.3 \AA$.

EJC- $\mathrm{AlF}_{3}$ gave the first structural insight into the mechanism of ATP hydrolysis in SF1 helicases. In UvrD, only minimal changes are observed in the transition state at the nucleotide binding site compared with the ATP state; however, these are amplified into movement of a "gating" helix at the binding pocket for the 3 ' end of the ssDNA (Lee and Yang 2006). The recent structures of UvrD were determined at a resolution, allowing observation of water molecules in the vicinity of the $\gamma$-phosphate, in contrast to the structure of PcrA. Comparison of PcrA and UvrD structures with those of the SF2 DEAD-box proteins VASA (Sengoku et al. 2006) and eIF4AIII (Andersen et al. 2006; Bono et al. 2006) in complex with RNA and ADPNP, reveals several highly conserved key structural features beyond their common use of the seven conserved motifs for DNA/RNA and ATP binding. First, the packing of the two RecA domains 1 and 2 in eIF4AIII are quite similar, not only to that observed in VASA (Andersen et al. 2006), but also to the packing of the two domains in PcrA (Fig. 5B) and UvrD (data not shown). As an example, eIF4AIII and PcrA can be superimposed with a root-mean-square deviation of $3.4 \AA$ over 284 common $C_{\alpha}$ positions from both RecA domains. Second, the direction of the singlestranded region is conserved in all four structures, the $5^{\prime}$ end is always at the second RecA domain, and the $3^{\prime}$ end at the first RecA domain. Third, the transition state geometry is rather similar in $\mathrm{EJC}-\mathrm{AlF}_{3}$ and $\mathrm{UvrD}-\mathrm{MgF}_{3}{ }^{-}$with two arginine "fingers" in contact with the $\beta$-phosphate and the planer $\gamma$-phosphate mimic. In addition, both structures contain a relay water $\mathrm{w}_{\mathrm{r}}$ (Fig. $2 \mathrm{~B}-\mathrm{C}$ ) located in between the glutamate of motif II, the $\gamma$-phosphate mimic, and the $\mathrm{Mg}^{2+}$ coordinating water. In contrast to both the EJCADPNP and VASA-ADPNP structures, the relay water is not observed in the UvrD-ADPNP structure; however, since there is sufficient space for it, this may be due to the lower resolution of the structure $(2.6 \AA)$ compared with that of the UvrD- $\mathrm{MgF}_{3}{ }^{-}$structure $(2.2 \AA)$. In summary, we predict that details of the mechanism of ATP hydrolysis are conserved between the two superfamilies of helicases. Many of these features are likely to be shared with the F1-ATPase, as described earlier (Andersen et al. 2006).

\section{MATERIALS AND METHODS}

\section{Plasmids and purifications}

Dbp5 was expressed from a pET30 vector (Novagen) that was modified by having a TEV protease cleavage site inserted after the N-terminal 6xHis tag. Plasmids encoding either eIF4AIII, MAGOH, and Y14 residues 51-176 (Y14D50), or the MLN51 fragment (MLN51-S), were identical to those previously described (Andersen et al. 2006). The plasmids were transformed into the BL21 Rosetta E. coli strain and cultures were grown at $37^{\circ} \mathrm{C}$ until an $\mathrm{OD}_{600}$ of $\sim 0.8$ and then induced overnight at $20^{\circ} \mathrm{C}$ with $1 \mathrm{mM}$ IPTG. Cells were resuspended in lysis buffer containing $20 \mathrm{mM}$ Tris $\mathrm{HCl}$ at $\mathrm{pH} 7.6,500 \mathrm{mM} \mathrm{KCl}$ (eIF4AIII and MLN51), $300 \mathrm{mM} \mathrm{KCl}$ (MAGOH/Y14), or $200 \mathrm{mM} \mathrm{NaCl}$ (Dbp5), $20 \mathrm{mM}$ Imidazole, 5 $\mathrm{mM} \mathrm{MgCl}_{2}, 0.5 \mathrm{mM} \beta$-mercaptoethanol ( $\beta$-ME), $1 \mathrm{mM}$ PMSF, complete protease inhibitor (Roche Diagnostics $\mathrm{GmbH}$ ), and $10 \%$ glycerol. The cells were opened by sonication and then centrifuged at $14,000 \mathrm{rpm}$ for $30 \mathrm{~min}$. Prior to loading on the $\mathrm{Ni}^{2+}$ charged IMAC column (GE Healthcare) the samples were filtered through a $0.45-\mu \mathrm{m}$ filter. The protein was eluted from the $\mathrm{Ni}^{2+}$ affinity column by running a gradient from $20-500 \mathrm{mM}$ imidazole in a buffer containing $20 \mathrm{mM}$ Tris- $\mathrm{HCl}$ at $\mathrm{pH} 7.6,500 \mathrm{mM} \mathrm{KCl}$ (eIF4AIII and MLN51), $300 \mathrm{mM} \mathrm{KCl} \mathrm{(MAGOH/Y14),} \mathrm{or} 200 \mathrm{mM}$ $\mathrm{NaCl}$ (Dbp5), $5 \mathrm{mM} \mathrm{MgCl}$, $0.5 \mathrm{mM} \beta$-ME, $0.5 \mathrm{mM}$ PMSF, and $10 \%$ glycerol. The affinity tag was removed with $1 / 300(w / w)$ TEV protease digestion on ice for $2 \mathrm{~h}$. The cleaved products were dialyzed overnight against $20 \mathrm{mM}$ Tris- $\mathrm{HCl}$ at $\mathrm{pH}$ 7.6, $500 \mathrm{mM}$ 
A EJC

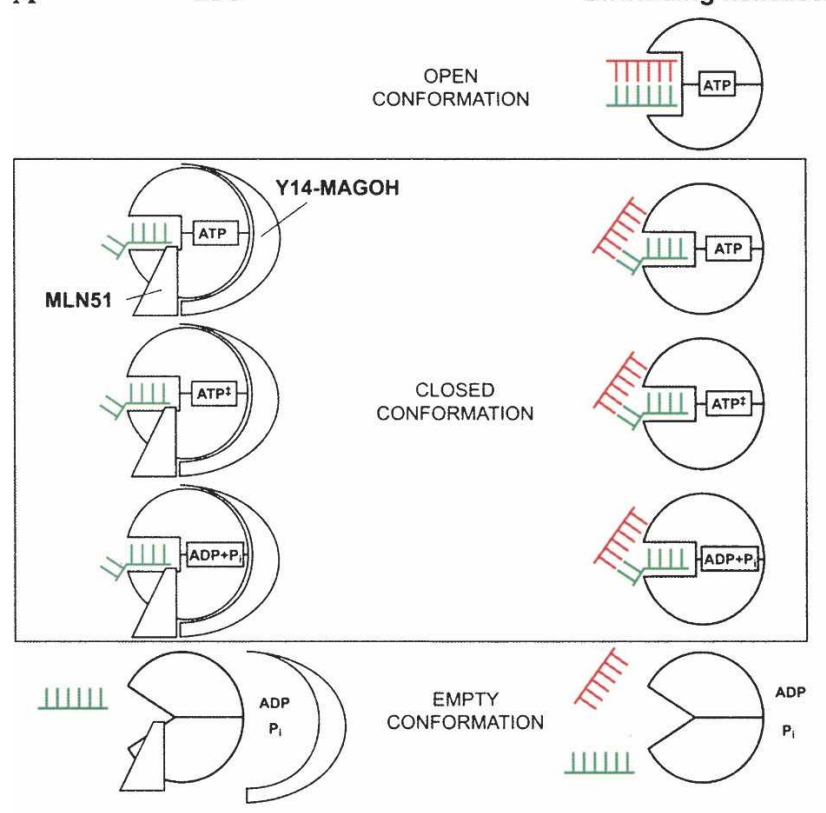

B
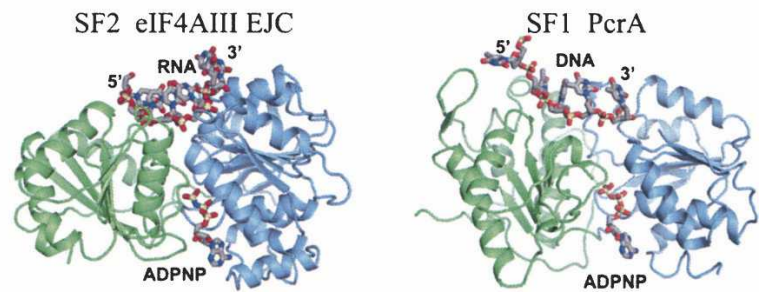

FIGURE 5. (A) A model for the role of ATP hydrolysis in relation to an unwinding helicase (right side) or the EJC (left side). Three states are shown, the open conformation, where the DEAD-box protein is bound to ATP and dsRNA, the closed conformation, where eIF4AIII and the helicase display a very similar structure and finally the empty conformation after dissociation. The ssRNA is depictured as a green comb, while the complementary strand in the dsRNA is a red comb. The kink in the ssRNA induced by the DEAD-box protein is indicated as a kink in the comb. See text for further discussion. (B) Comparison of the closed ATP-RNA bound conformation of eIF4AIII within the EJC (left panel) and the closed conformation of PcrA in the ATPDNA complex (right panel) (pdb entry 3PJR). For clarity, only the two RecA domains ( $\mathrm{N}$-terminal blue, $\mathrm{C}$-terminal green) are shown for both proteins, and only the singlestranded region of the DNA is shown for PcrA.

$\mathrm{KCl}$ (eIF4AIII and MLN51), $300 \mathrm{mM} \mathrm{KCl}$ (MAGOH/Y14), or 200 $\mathrm{mM} \mathrm{NaCl}$ (Dbp5), $5 \mathrm{mM} \mathrm{MgCl}_{2}, 0.5 \mathrm{mM} \beta$-ME, and $10 \%$ glycerol. The sample was loaded on the $\mathrm{Ni}^{2+}$ affinity column again and the flow-through containing essentially pure protein was collected. Dbp5 was diluted four times in water and further purified on a Source 15Q using the following buffer, $20 \mathrm{mM}$ Tris$\mathrm{HCl}$ at $\mathrm{pH} 8,10 \%$ glycerol, $50 \mathrm{mM} \mathrm{NaCl}, 0.5 \mathrm{mM}$ dithiotretiol (DTT), and eluted by increasing the $\mathrm{NaCl}$ concentration in a linear gradient to $200 \mathrm{mM}$.

\section{Reconstitution of EJC}

For reconstitution of the EJC, the eIF4AIII and MLN51 were mixed in an equimolar ratio, while the MAGOHY/14 heterodimer was added in excess, in a buffer containing $100 \mathrm{mM}$ Tris- $\mathrm{HCl}$ at $\mathrm{pH}$ 7.6, $5 \mathrm{mM} \mathrm{MgCl}_{2}, 1 \mathrm{mM}$ DTT, $150 \mathrm{mM} \mathrm{KCl}, 1 \mathrm{mM} \mathrm{ADP}$ (A2754, Sigma), $1 \mathrm{mM} \mathrm{AlCl} 3$ (21,747, Acros Organics), $10 \mathrm{mM}$ $\mathrm{NaF}$ (71,519, Fluka BioChemika), and polyU (P9528, Sigma; 1/3 $\left.\mathrm{w}_{\text {rna }} / \mathrm{w}_{\text {protein }}\right)$. The mixture was incubated at $18^{\circ} \mathrm{C}$ overnight and then treated with RNase A (0.1 mg RNase A (R5500, Sigma)/10 mg EJC) for $30 \mathrm{~min}$ at $18^{\circ} \mathrm{C}$ to cleave unprotected RNA. Ammonium sulphate (AmS) was added to $1.4 \mathrm{M}$ and the sample loaded on a Source isopropyl column (GE Healthcare). The complex was eluted by running a gradient from 1.4-0 M AmS in a buffer containing $20 \mathrm{mM}$ Tris $\mathrm{HCl}$ at $\mathrm{pH}$ 7.6, $5 \mathrm{mM} \mathrm{MgCl}_{2}$, and $1 \mathrm{mM}$ DTT. Fractions containing purified complex were precipitated with AmS and resuspended in crystallization buffer (20 mM Tris at $\mathrm{pH} 7.6,150 \mathrm{mM} \mathrm{KCl}, 5 \mathrm{mM} \mathrm{MgCl}_{2}$, and $1 \mathrm{mM}$ DTT) to $5 \mathrm{mg} / \mathrm{mL}$. Crystals were grown in hanging drops against a reservoir containing 7\% PEG3350, $50 \mathrm{mM}$ Tris $\mathrm{HCl}$ at $\mathrm{pH} 8.8,200$ $\mathrm{mM}$ NaAcetate. The crystals were transferred to a cryoprotection buffer (25\% Ethylene Glycol, 4\% PEG3350, $50 \mathrm{mM}$ Tris $\mathrm{HCl}$ at $\mathrm{pH} 8.8$ ) and frozen in liquid nitrogen.

\section{Structure determination and refinement}

Diffraction data were processed and scaled using the XDS package (Kabsch 2001) (Table 1). The structure of the EJC-AlF 3 was solved by molecular replacement using PHASER (Storoni et al. 2004) with the EJC (Andersen et al. 2006) as a search model. Model building and averaging of density maps were done in the program "O" (Jones et al. 1991) and the fitted models were refined with CNS (Brünger et al. 1998) and PHENIX.REFINE (Adams et al. 2002). Molecular graphics figures were prepared with PYMOL (DeLano 2002).

\section{Streptavidin pull-down assay}

The streptavidin agarose beads (High Capacity Streptavidin Agarose Resin, Pierce), $20 \mu \mathrm{L} 50 \%$ slurry per reaction, were washed in $0.5 \mathrm{~mL}$ binding buffer $(20 \mathrm{mM}$ HEPES-NaOH at $\mathrm{pH}$ 7.2, $125 \mathrm{mM} \mathrm{NaCl}, 5 \mathrm{mM} \mathrm{MgCl} 2,2,5 \%$ glycerol, $1 \mathrm{mM}$ DTT for EJC, and $20 \mathrm{mM}$ HEPES-NaOH at pH 7.2, $100 \mathrm{mM} \mathrm{NaCl}, 5 \mathrm{mM}$ $\mathrm{MgCl}_{2}, 1 \mathrm{mM} \beta$-ME for Dbp5) three times using an Eppendorf centrifuge to pellet the beads by spinning for $2 \mathrm{~min}$ at $3 \mathrm{k} \mathrm{rpm}$. The beads were aliquoted and either $0.2 \mathrm{nmol}$ for EJC or $0.1 \mathrm{nmol}$ for Dbp5 of polyU $\mathrm{U}_{30}$-biotin (Dharmacon) per reaction together with the proteins and nucleotides of interest were mixed and incubated as described in the figure legend after which the beads were washed three times using $0.5 \mathrm{~mL}$ binding buffer. The bound protein was eluted by boiling the beads in $2.5 \mathrm{xSDS}$ sample buffer followed by separation on a $12 \%$ SDS gel, which was Coomassie stained. The concentrations of nucleotides/analogs were $1 \mathrm{mM}$ for ADPNP, ADP, ATP, $\mathrm{BeSO}_{4}$, and $\mathrm{AlCl}_{3}$. $\mathrm{NaF}$ was added to a final concentration of $10 \mathrm{mM}$ and $\mathrm{KH}_{2} \mathrm{PO}_{4} / \mathrm{K}_{2} \mathrm{HPO}_{4}$ to a final concentration of $5 \mathrm{mM}$.

\section{Thin-layer chromatography}

EJC assembled with either $\left[\alpha-{ }^{32} \mathrm{P}\right]$ or $\left[\gamma^{-32} \mathrm{P}\right]$ ATP was purified on calmodulin beads by using TAP-MAGOH/Y14 as bait as follows: $2 \mu \mathrm{g}$ of each EJC proteins were mixed in binding buffer BB-125 (20 mM HEPES at pH 7.4, $5 \mathrm{mM} \mathrm{MgCl}_{2}, 2,5 \%$ glycerol, $1 \mathrm{mM}$ DTT, $125 \mathrm{mM} \mathrm{NaCl}$ ) supplemented with $1 \mathrm{mM}$ cold ATP, $5 \mu \mathrm{Ci}$ of $\left[\alpha-{ }^{32} \mathrm{P}\right]$ or $\left[\gamma^{-32} \mathrm{P}\right]$ ATP $\left(3000 \mathrm{Ci} \mathrm{mmol}{ }^{-1}\right.$, Perkin-Elmer $), 170 \mathrm{nM}$ 
47-mer ssRNA ( $3^{\prime}$ end biotinylated RNA purchased from Dharmacon), and incubated for $20 \mathrm{~min}$ or $60 \mathrm{~min}$ at $30^{\circ} \mathrm{C}$ in a final volume of $25 \mu \mathrm{L}$. To the mix was added $12 \mu \mathrm{L}$ of Calmodulin Resin (50\% slurry, Stratagen) and $250 \mu \mathrm{L}$ of BB-250 supplemented with $0.1 \mathrm{mM}$ of cold ATP to eliminate non specific binding of ATP to the beads. After incubation for $1 \mathrm{~h}$ at $4^{\circ} \mathrm{C}$, the resin was washed four times with $500 \mu \mathrm{L}$ BB-250, $0.1 \mathrm{mM}$ ATP. Proteins were eluted with $20 \mu \mathrm{L}$ of $10 \mathrm{mM}$ Tris at $\mathrm{pH} 7.5,20 \mathrm{mM}$ EGTA. SDS was added to a final concentration of $0.1 \%$ and proteins were denatured at $65^{\circ} \mathrm{C}$, and $5 \mu \mathrm{L}$ of the resulting solution was spotted on PEI-cellulose. The TLC plate was developed in $0.3 \mathrm{M} \mathrm{K}_{2} \mathrm{HPO}_{4}$ at $\mathrm{pH} \mathrm{7.6}$, and the radioactivity was visualized and quantified with a phosphorimager (Molecular Dynamics).

\section{ACKNOWLEDGMENTS}

We are grateful to G. Hartvigsen for technical assistance, E. Jankowsky for discussion and suggestions, and the staffs at ESRF and SLS for help with data collection. K.H.N. was supported by the Danish National Research Foundation and the Alfred Benzon Foundation. G.R.A. was supported by FNU and the Danish National Research Foundation. H.C. and H.L.H. were supported by the CNRS and the Agence Nationale de la Recherche. Coordinates and structure factors have been deposited at the RCSB protein data bank with the ID code 3 EX7.

Received July 24, 2008; accepted October 20, 2008.

\section{REFERENCES}

Adams, P.D., Grosse-Kunstleve, R.W., Hung, L.W., Ioerger, T.R., McCoy, A.J., Moriarty, N.W., Read, R.J., Sacchettini, J.C., Sauter, N.K., and Terwilliger, T.C. 2002. PHENIX: Building new software for automated crystallographic structure determination. Acta Crystallogr. D Biol. Crystallogr. 58: 1948-1954.

Andersen, C.B.F., Ballut, L., Johansen, J.S., Chamieh, H., Nielsen, K.H., Oliveira, C., Pedersen, J.S., Seraphin, B., Le Hir, H., and Andersen, G.R. 2006. Structure of the exon junction core complex with a trapped DEAD-box ATPase bound to RNA. Science 313: 1968-1972.

Ballut, L., Marchadier, B., Baguet, A., Tomasetto, C., Seraphin, B., and Le Hir, H. 2005. The exon junction core complex is locked onto RNA by inhibition of eIF4AIII ATPase activity. Nat. Struct. Mol. Biol. 12: 861-869.

Bizebard, T., Ferlenghi, I., Iost, I., and Dreyfus, M. 2004. Studies on three E. coli DEAD-box helicases point to an unwinding mechanism different from that of model DNA helicases. Biochemistry 43: 7857-7866.

Bono, F., Ebert, J., Lorentzen, E., and Conti, E. 2006. The crystal structure of the exon junction complex reveals how it maintains a stable grip on mRNA. Cell 126: 713-725.

Braig, K., Menz, R.I., Montgomery, M.G., Leslie, A.G., and Walker, J.E. 2000. Structure of bovine mitochondrial F(1)-ATPase inhibited by $\mathrm{Mg}^{2+} \mathrm{ADP}$ and aluminium fluoride. Structure 8: $567-$ 573.

Brünger, A.T., Adams, P.D., Clore, G.M., DeLano, W.L., Gros, P., Grosse-Kunstleve, R.W., Jiang, J.-S., Kuszewski, J., Nilges, M., Pannu, N.S., et al. 1998. Crystallography \& NMR system: A new software suite for macromolecular structure determination. Acta Crystallogr. D Biol. Crystallogr. 54: 905-921.

Caruthers, J.M. and McKay, D.B. 2002. Helicase structure and mechanism. Curr. Opin. Struct. Biol. 12: 123-133.
Coleman, D.E., Berghuis, A.M., Lee, E., Linder, M.E., Gilman, A.G., and Sprang, S.R. 1994. Structures of active conformations of Gi $\alpha$ 1 and the mechanism of GTP hydrolysis. Science 265: 1405-1412.

Cordin, O., Banroques, J., Tanner, N.K., and Linder, P. 2006. The DEAD-box protein family of RNA helicases. Gene 367: 17-37.

DeLano, W.L. 2002. The PyMOL user's manual. DeLano Scientific, San Carlos, CA.

Fairman, M.E., Maroney, P.A., Wang, W., Bowers, H.A., Gollnick, P., Nilsen, T.W., and Jankowsky, E. 2004. Protein displacement by DExH/D "RNA helicases" without duplex unwinding. Science 304: 730-734.

Graham, D.L., Lowe, P.N., Grime, G.W., Marsh, M., Rittinger, K., Smerdon, S.J., Gamblin, S.J., and Eccleston, J.F. 2002. $\mathrm{MgF}_{3}{ }^{-}$as a transition state analog of phosphoryl transfer. Chem. Biol. 9: 375381.

Henn, A., Cao, W., Hackney, D.D., and De La Cruz, E.M. 2008. The ATPase cycle mechanism of the DEAD-box rRNA helicase, DbpA. J. Mol. Biol. 377: 193-205.

Jankowsky, E., Gross, C.H., Shuman, S., and Pyle, A.M. 2001. Active disruption of an RNA-protein interaction by a DExH/D RNA helicase. Science 291: 121-125.

Jones, T.A., Cowan, S., Zou, J.-Y., and Kjeldgaard, M. 1991. Improved methods for building protein models in electron density maps and the location of errors in these models. Acta Crystallogr. A 47: 110119.

Kabsch, W. 2001. XDS. In International tables for crystallography (eds. M.G. Rossmann and E. Arnold), chap. 25.22.29. Kluwer Academic Publishers, Dordrecht, The Netherlands.

Kagawa, R., Montgomery, M.G., Braig, K., Leslie, A.G., and Walker, J.E. 2004. The structure of bovine F1-ATPase inhibited by ADP and beryllium fluoride. EMBO J. 23: 2734-2744.

Lee, J.Y. and Yang, W. 2006. UvrD helicase unwinds DNA one base pair at a time by a two-part power stroke. Cell 127: 1349-1360.

Le Hir, H. and Andersen, G.R. 2008. Structural insights into the exon junction complex. Curr. Opin. Struct. Biol. 18: 112-119.

Le Hir, H., Izaurralde, E., Maquat, L.E., and Moore, M.J. 2000. The spliceosome deposits multiple proteins 20-24 nucleotides upstream of mRNA exon-exon junctions. EMBO J. 19: 6860-6869.

Lund, M.K. and Guthrie, C. 2005. The DEAD-box protein Dbp5p is required to dissociate Mex67p from exported mRNPs at the nuclear rim. Mol. Cell 20: 645-651.

Menz, R.I., Walker, J.E., and Leslie, A.G. 2001. Structure of bovine mitochondrial $\mathrm{F}(1)$-ATPase with nucleotide bound to all three catalytic sites: Implications for the mechanism of rotary catalysis. Cell 106: 331-341.

Nassar, N., Hoffman, G.R., Manor, D., Clardy, J.C., and Cerione, R.A. 1998. Structures of Cdc42 bound to the active and catalytically compromised forms of Cdc42GAP. Nat. Struct. Biol. 5: 1047-1052.

Noble, C.G. and Song, H. 2007. MLN51 stimulates the RNA-helicase activity of eIF4AIII. PLoS One 2: e303. doi: 10.1371/journal. pone.0000303.

Pan, X., Eathiraj, S., Munson, M., and Lambright, D.G. 2006. TBCdomain GAPs for Rab GTPases accelerate GTP hydrolysis by a dual-finger mechanism. Nature 442: 303-306.

Ray, B.K., Lawson, T.G., Kramer, J.C., Cladaras, M.H., Grifo, J.A., Abramson, R.D., Merrick, W.C., and Thach, R.E. 1985. ATPdependent unwinding of messenger RNA structure by eukaryotic initiation factors. J. Biol. Chem. 260: 7651-7658.

Rogers Jr., G.W., Richter, N.J., and Merrick, W.C. 1999. Biochemical and kinetic characterization of the RNA helicase activity of eukaryotic initiation factor 4A. J. Biol. Chem. 274: 12236-12244.

Rozen, F., Edery, I., Meerovitch, K., Dever, T.E., Merrick, W.C., and Sonenberg, N. 1990. Bidirectional RNA helicase activity of eucaryotic translation initiation factors 4A and 4F. Mol. Cell. Biol. 10: $1134-1144$.

Scheffzek, K., Ahmadian, M.R., Kabsch, W., Wiesmuller, L., Lautwein, A., Schmitz, F., and Wittinghofer, A. 1997. The RasRasGAP complex: Structural basis for GTPase activation and its loss in oncogenic Ras mutants. Science 277: 333-338. 
Scrima, A. and Wittinghofer, A. 2006. Dimerization-dependent GTPase reaction of MnmE: How potassium acts as GTPaseactivating element. EMBO J. 25: 2940-2951.

Sengoku, T., Noreki, O., Nakamura, A., Kobayashi, S., and Shigeyuki, Y. 2006. Structural basis for RNA unwinding by the DEAD-box protein Drosophila vasa. Cell 125: 287-300.

Shu, Z., Vijayakumar, S., Chen, C.F., Chen, P.L., and Lee, W.H. 2004. Purified human SUV3p exhibits multiple-substrate unwinding activity upon conformational change. Biochemistry 43: 4781-4790.

Singleton, M.R. and Wigley, D.B. 2002. Modularity and specialization in superfamily 1 and 2 helicases. J. Bacteriol. 184: 1819-1826.

Snay-Hodge, C., Colot, H., Goldstein, A., and Cole, C. 1998. Dbp5p/ Rat8p is a yeast nuclear pore-associated DEAD-box protein essential for RNA export. EMBO J. 17: 2663-2676.

Stebbins, C.E. and Galan, J.E. 2000. Modulation of host signaling by a bacterial mimic: Structure of the Salmonella effector SptP bound to Rac1. Mol. Cell 6: 1449-1460.

Storoni, L.C., McCoy, A.J., and Read, R.J. 2004. Likelihood-enhanced fast rotation functions. Acta Crystallogr. D Biol. Crystallogr. 60: 432-438.

Svitkin, Y.V., Pause, A., Haghighat, A., Pyronnet, S., Witherell, G., Belsham, G.J., and Sonenberg, N. 2001. The requirement for eukaryotic initiation factor $4 \mathrm{~A}(\mathrm{elF} 4 \mathrm{~A})$ in translation is in direct proportion to the degree of mRNA 5 ' secondary structure. RNA 7: 382-394.

Tange, T.O., Nott, A., and Moore, M.J. 2004. The ever-increasing complexities of the exon junction complex. Curr. Opin. Cell Biol. 16: $279-284$.
Tran, E.J., Zhou, Y., Corbett, A.H., and Wente, S.R. 2007. The DEADbox protein Dbp5 controls mRNA export by triggering specific RNA:protein remodeling events. Mol. Cell 28: 850-859.

Velankar, S.S., Soultanas, P., Dillingham, M.S., Subramanya, H.S., and Wigley, D.B. 1999. Crystal structures of complexes of PcrA DNA helicase with a DNA substrate indicate an inchworm mechanism. Cell 97: 75-84.

Wagner, J.D., Jankowsky, E., Company, M., Pyle, A.M., and Abelson, J.N. 1998. The DEAH-box protein PRP22 is an ATPase that mediates ATP-dependent mRNA release from the spliceosome and unwinds RNA duplexes. EMBO J. 17: 2926-2937.

Weirich, C.S., Erzberger, J.P., Flick, J.S., Berger, J.M., Thorner, J., and Weis, K. 2006. Activation of the $\mathrm{DExD} / \mathrm{H}$-box protein $\mathrm{Dbp} 5$ by the nuclear-pore protein Gle1 and its coactivator InsP6 is required for mRNA export. Nat. Cell Biol. 8: 668-676.

Wittinghofer, A. 2006. Phosphoryl transfer in Ras proteins, conclusive or elusive? Trends Biochem. Sci. 31: 20-23.

Wurtele, M., Wolf, E., Pederson, K.J., Buchwald, G., Ahmadian, M.R., Barbieri, J.T., and Wittinghofer, A. 2001. How the Pseudomonas aeruginosa ExoS toxin downregulates Rac. Nat. Struct. Biol. 8: $23-$ 26.

Yang, Q. and Jankowsky, E. 2005. ATP- and ADP-dependent modulation of RNA unwinding and strand annealing activities by the DEAD-box protein DED1. Biochemistry 44: 1359113601.

Yang, Q. and Jankowsky, E. 2006. The DEAD-box protein Ded1 unwinds RNA duplexes by a mode distinct from translocating helicases. Nat. Struct. Mol. Biol. 13: 981-986. 

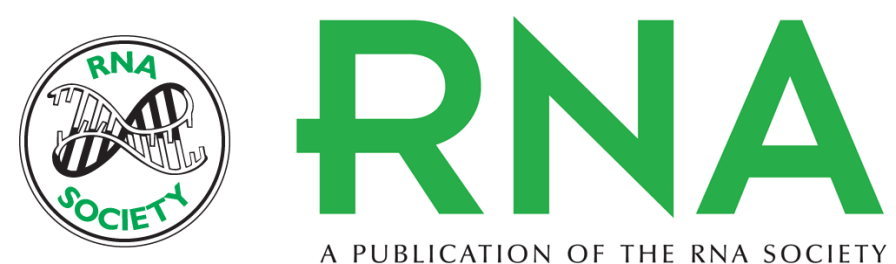

A PUBLICATION OF THE RNA SOCIETY

\section{Mechanism of ATP turnover inhibition in the EJC}

Klaus H. Nielsen, Hala Chamieh, Christian B.F. Andersen, et al.

RNA 2009 15: 67-75 originally published online November 25, 2008

Access the most recent version at doi:10.1261/rna.1283109

\section{References This article cites 45 articles, 13 of which can be accessed free at: http://rnajournal.cshlp.org/content/15/1/67.full.html\#ref-list-1}

\section{License}

Email Alerting Receive free email alerts when new articles cite this article - sign up in the box at the Service top right corner of the article or click here.

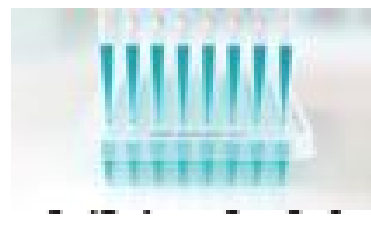

\section{Providing Precise Solutions for} your research.

To subscribe to RNA go to:

http://rnajournal.cshlp.org/subscriptions 